\title{
A constituição do sistema municipal de Seropédica-RJ*1
}

\author{
The constitution of the municipal system \\ Seropédica/RJ
}

\section{Maria Angélica da Gama Cabral Coutinho*2}

Palavras-chave: Sistema municipal de ensino; Seropédica-RJ; Escola pública; UFRRJ.
Resumo: $O$ presente trabalho pretende identificar e analisar as origens da criação das primeiras escolas no município de Seropédica/RJ e estabelece o limite temporal do ano de 2010. A educação que hoje conhecemos na referida cidade, município da região metropolitana do Rio de Janeiro, tem sua origem no município de Itaguaí, ao qual pertencia como um distrito. Seropédica é um pequeno município da região metropolitana do Rio de Janeiro, muito pobre, de característica agrícola e visível precariedade nas condições de vida da população. Embora seja uma cidade-dormitório, pois atende a grande quantitativo de trabalhadores que têm seus empregos localizados em outros municípios próximos, é conhecida, também, como cidade universitária. As unidades escolares, tanto as escolas da rede privada, como as pertencentes às redes estadual e municipal - esta última, foco da análise ora apresentada - surgiram a partir da instalação da atual Universidade Federal Rural do Rio de Janeiro na região. Ao final da investigação, o estudo desvelou que, a despeito de as instituições escolares terem surgido da necessidade criada pela presença da instituição de ensino superior, a relação entre as escolas públicas municipais e a universidade é ainda incipiente. Sinaliza, assim, que a universidade mantém-se distanciada de sua cidade, apartada de seu cotidiano, do dia a dia da população, e contribuindo ainda muito pouco para o seu desenvolvimento e a educação de sua gente.

\footnotetext{
*1 Recebido em 13/07/2015. Aceito para publicação em: 02/12/2015. A pesquisa ora apresentada é fragmento de uma investigação, tese apresentada e aprovada no Programa de Pós-Graduação em Educação (PROPED) da Universidade do Estado do Rio de Janeiro, cujo tema refere-se à relação entre a Universidade Federal Rural do Rio de Janeiro e a educação municipal de Seropédica.

*2 Professora Adjunta na Universidade Federal do Rio de Janeiro, Doutora pelo ProPEd/UERJ. E.mail: m_angelicacoutinho@yahoo.com.br.
} 
Keywords: Abstract: The aim of this work is to identify and analyze Municipal education

system; Seropédica-RJ; Public school; UFRRJ. the creation of the first schools in the city of Seropédica/RJ, a city that used to be a district of Itaguai in the past. So, education the way we know today in Seropédica (which now belongs to Rio de Janeiro metropolitan region) has its origin in the city of Itaguaí. Seropédica is a very poor city, with agricultural characteristics and precarious life condition of the population. Although being a dormitory town, because it serves a great number or workers whose jobs are located in other cities, it is also known as a university city. Both private and public schools - these ones the focus of this analysis - were created after the installation of the Rio de Janeiro Federal Rural University on the region. At the end of the investigation, the study revealed that despite the schools having being created from the necessity the university aroused, the relation between State and City schools and the university is still incipient. It shows the university keeps distant from its town, apart from its quotidian, from the population everyday life, contributing very little for its development and people's education.

$\mathrm{H}$ istoricamente, a gênese da escola pública guardou por muito tempo a marca do centralismo de um Estado que pretendia monopolizar os esforços educacionais da sociedade, reduzindo-os a seus objetivos "civilizadores", "modernizadores" ou disciplinares. No entanto, a escola não é somente o instrumento de construção de uma ordem autoritária; ela também é o reflexo do processo sociopolítico que define a sociedade.

A escola pública é o locus em que diferentes projetos de sociedade se confrontam e disputam a possibilidade de construir uma nova sociedade. Nessa instituição convivem profissionais da educação que, em alguns casos, discutem a possibilidade de constituir a escola como uma instituição voltada para a construção de uma sociedade socialmente referenciada, onde o debate sobre a transformação social assume um lugar privilegiado. Porém, a instituição escolar precisa enfrentar o projeto que a cada dia se estabelece e se fortalece em seu interior por meio da "disseminação do ideário neoliberal e de reestruturação produtiva (...) como decorrentes da crise e do esgotamento do Estado keynesiano desenvolvimentista $(. .)^{\prime \prime}$, conforme analisam Souza e Faria (2003, p. 52).

Para o desenvolvimento do trabalho, os arquivos escolares constituíramse em fontes muito ricas em informações, permitindo o fornecimento de documentos que possibilitaram a reconstrução histórica das escolas. Assim como os sujeitos que passaram pela instituição, sejam eles professores, funcionários e alunos. Tais arquivos preservam a memória da escola, contribuindo para a escrita da história da educação da região em que se encontra inserida, sendo também fonte para a memória local. 
Marc Bloch (1974, p. 61) comentou acerca dos documentos, também chamados testemunhos ou mesmo ainda fontes, como uma variedade de possibilidades: "É quase infinita a diversidade dos testemunhos históricos. Tudo quanto o homem diz ou escreve, tudo quanto fabrica, tudo em quanto toca pode e deve informar a seu respeito". Febvre (1977, p. 212), nos apresenta sua visão sobre o tema:

A história faz-se com documentos escritos, sem dúvida. Quando eles existem. Mas ela pode fazer-se sem documentos escritos, se os não houver. Com tudo o que o engenho do historiador pode permitir-lhe utilizar para fabricar o seu mel, à falta das flores habituais. Portanto, com palavras. Com signos. Com paisagens e telhas. Com formas de cultivo e ervas daninhas. Com eclipses da lua e cangas de bois. Com exames de pedras por geólogos e análises de espadas de metal por químicos.

Desta forma, a pesquisa buscou recuperar o processo histórico da educação local. As dificuldades foram muito grandes, pois a guarda de papéis não ocorre de maneira adequada, o que prejudica, e às vezes até impossibilita, o manuseio. Muitas vezes a investigação fundamentou-se em documentos não escritos, na ausência dos papéis e dos testemunhos escritos. Todavia, as falas foram cruciais, elas moveram e encaminharam os estudos.

Os acervos de muitas escolas, algumas delas visitadas durante a pesquisa de campo, são chamados de "Arquivos Mortos", e estão em condições bastante precárias. Tal acervo frequentemente se encontra em salas muito úmidas e em cantinhos pouco apropriados, em prateleiras e no alto de armários desprotegidos da poeira e de insetos. Não diferem muito da situação das escolas de outros municípios.

Algumas escolas de Seropédica tiveram seus arquivos em parte ou totalmente destruídos pela ação do tempo, ou sofreram com incêndios, ou ainda enchentes. As dificuldades de armazenamento dos documentos por si sós já determinam sua má conservação.

Ao mesmo tempo, observa-se que nas instituições escolares existe a preocupação em guardar os apontamentos escolares, sobretudo os que se referem aos alunos; entretanto, não são observadas as condições mais adequadas para esse arquivamento. Assim, os documentos, geralmente, estão localizados

(...) em local inadequado, pois não comporta o acervo, estando muitos livros depositados no chão e outra metade dos documentos armazenados em armários situados nos corredores, os documentos mais antigos que datam de 1947, já possuem certa catalogação e estão guardados em caixas de papelão. (FREITAS, s/d, 6)

De todo modo, os arquivos existentes nas escolas de Seropédica foram fontes importantes para a compreensão das instituições escolares e do sistema público de ensino em um município fluminense tão recente e que apresenta características tão singulares relacionadas à história da UFRRJ.

A educação que hoje conhecemos em Seropédica teve início nos limites municipais de Itaguaí. Todas as escolas municipais de Itaguaí localizadas no antigo distrito foram transferidas para a nova esfera municipal: eram dezenove unidades escolares, distribuídas por vários bairros e também localizadas na área rural dos limites territoriais do município, além do Centro de Atenção Integral à 
Criança (CAIC) Paulo Dacorso Filho, um caso excepcional, a ser analisado mais adiante.

Até a emancipação, a Prefeitura de Itaguaí construiu, com seus próprios recursos, oito unidades escolares, como se observa pelo documento fornecido pela Secretaria Municipal de Educação (SME) de Seropédica. Duas outras foram construídas por moradores, outra funciona em prédio estadual, e, por fim, as oito restantes são escolas estaduais que foram municipalizadas ${ }^{2}$, em sua maior parte, no ano de 1993.

Por outro lado, observando-se a localização geográfica das unidades escolares, havia uma distribuição racional, pois foram construídas situando-se nos diferentes bairros do distrito, buscando atender, mesmo que de forma insuficiente, à população local.

Tal carência de escolas fica confirmada quando se observa a mobilização de duas comunidades com 0 objetivo de construir mais duas unidades escolares. O primeiro caso é o da atualmente denominada Escola Municipal Professor Paulo Freire, em homenagem ao educador brasileiro que tanto lutou pela educação popular. Diante da ausência de uma ação mais direta por parte da administração municipal, esta unidade foi implantada pela Associação de Moradores do Assentamento "Sol da Manhã", por meio de um mutirão em 1985, com a finalidade de atender em torno de vinte crianças, filhos e filhas dos assentados do Movimento dos Trabalhadores Sem Terra (MST) instalados na região. Em 1992, a escola passou a ser administrada pela esfera municipal, através da Prefeitura de Itaguaí, conforme dados oficiais fornecidos pela SME.

A Escola Municipal Nossa Senhora de Nazareth (homenagem à padroeira local) também é outro exemplo de escola construída por moradores, em uma área em que o poder público não havia ainda garantido um espaço oficial de escolarização para a população.

Dentre as escolas construídas no período anterior à emancipação, as mais antigas, dentre aquelas cujas datas de inauguração foram comprovadas, são a Escola Estadual Municipalizada (E. E. M.) Professora Creuza de Paula Bastos e a Escola Municipal (E. M.) Panaro Figueira.

A E. E. M. Creuza de Paula Bastos foi fundada no ano de 1949 pelo governo estadual, em terras pertencentes ao antigo Serviço de Alimentação e Previdência Social (SAPS) ${ }^{3}$, atualmente terreno de propriedade da UFRRJ.

Anteriormente, a instituição chamava-se Escola Roberto Silveira, como se observou na leitura de documento encontrado na escola, e foi municipalizada em 1994. Esta unidade situa-se no bairro conhecido por Incra ${ }^{4}$, e a escolha de

\footnotetext{
${ }^{2}$ Atualmente, após a política de municipalização implementada no Rio de Janeiro, há apenas oito colégios estaduais no município de Seropédica. São eles: CIEP 155 Nelson Antelo Romar, CIEP 156 Doutor Alberto Sabin, CE Barão De Tefé, CE Presidente Dutra, CE Alice De Souza Bruno, CE Alvarina De Carvalho Janotti, CE Professor Roberto Lyra, CE Professor Waldemar Raythe.

3 O Serviço de Alimentação e Previdência Social era um órgão do antigo Ministério do Trabalho e Comércio.

${ }^{4} \mathrm{O}$ nome do bairro Incra, em Seropédica, é uma clara referência ao Instituto Nacional de Colonização e Reforma Agrária/INCRA, uma autarquia federal criada em 1970 com a finalidade de promover a reforma agrária em terras brasileiras.
}

Caderno eletrônico de Ciências Sociais, Vitória, v. 3, n. 2, p. 67-80. 
seu nome atual é uma homenagem à professora que exerceu o primeiro cargo de direção desta unidade escolar.

A Escola Municipal Panaro Figueira foi inaugurada em 1952 pela prefeitura de Itaguaí e funcionava em um antigo prédio doado para as atividades escolares, sendo reinaugurada em 2007, após construção de novo edifício no mesmo local. A despeito de muitas tentativas, a única informação acerca do nome da escola veio de um professor, o qual afirmou que o patrono da instituição é um antigo vereador do município de Itaguaí. Entretanto, como em outros casos, tal afirmação não conseguiu ser comprovada por documento oficial da escola.

Outra escola das mais antigas de Seropédica é a E. E. M. Francisco Rodrigues Cabral, construída em 1969 pela Secretaria Estadual de Educação. Ela situa-se às margens da Rodovia Presidente Dutra, mais precisamente no Bairro Cabral - zona rural do município. A partir de informações de professores da escola e de moradores de Seropédica, a pesquisa identificou que a escola recebeu o nome do morador mais antigo da comunidade, Francisco Rodrigues Cabral, que trabalhou na abertura da antiga estrada Rio-São Paulo e doou o terreno para a edificação da unidade escolar.

A Escola Estadual Municipalizada Professor Paulo de Assis Ribeiro também é antiga, apesar de não ter sido possível comprovar a data de sua criação. Entretanto, nas pesquisas realizadas no chamado Arquivo Morto da instituição, foram encontrados Diários de Classe, assim como fichas e boletins de alunos que evidenciaram dados históricos. Dentre esses, alguns dos mais antigos documentos escolares encontrados datam de 1972 e referem-se à Escola Rural de Santa Alice, denominação da área rural onde esta se localiza, suscitando a dúvida se tais documentos pertencem à mesma escola com nome diferente, ou se apenas estão ali guardados. Mais tarde, entre 1974 e 1976, a instituição escolar passou a se chamar Escola Reunida São Francisco de Paula, e posteriormente recebeu o nome que assume até os dias de hoje. O Prof. Paulo Ribeiro, patrono da escola, engenheiro civil do MEC, foi o primeiro presidente do INCRA, entre os anos de 1964 e 1967, tendo sido, ainda, professor da PUC-RJ e um grande incentivador da pesquisa no âmbito da Educação. Em 1993, poucos anos antes da criação de Seropédica, a escola foi municipalizada.

A partir dos dados levantados, e apesar da precariedade da documentação existente, avalia-se que as primeiras unidades escolares apresentadas nasceram motivadas pela transferência da Universidade de seu campus original, situado na cidade do Rio de Janeiro, para a região de Seropédica.

Segue-se a listagem ${ }^{5}$ das escolas - escolas municipais (E. M.) e escolas estaduais municipalizadas (E. E. M.) - que integravam a rede municipal, quando ainda um distrito de Itaguaí, e que compuseram a rede oficial da cidade no momento de sua emancipação, em 1997:

\footnotetext{
${ }^{5} \mathrm{Na}$ lista aparecem escolas fundadas pelo município de Itaguaí e escolas criadas pela Secretaria de Estado de Educação/RJ, e que foram municipalizadas ante a emancipação de Seropédica.
}

Caderno eletrônico de Ciências Sociais, Vitória, v. 3, n. 2, p. 67-80. 
Quadro 1: Escolas da rede municipal de Itaguaítransferidas para a rede de Seropédica ${ }^{6}$

\begin{tabular}{|c|c|}
\hline Origem & Nome \\
\hline EEM & Profa Creuza de Paula Bastos \\
\hline EM & Panaro Figueira \\
\hline EEM & Francisco Rodrigues Cabral \\
\hline EEM & Coletivo Santa Alice \\
\hline EEM & Bananal \\
\hline EM & José de Abreu \\
\hline EM & Pastor Gerson Ferreira da Costa \\
\hline EM & Prof. Paulo Freire \\
\hline EM & Luiz Leite de Brito \\
\hline EEM & Olavo Bilac \\
\hline EEM & Quintino Bocaiúva \\
\hline EEM & Santa Sofia (alunos da extinta Oscar Vasconcelos) \\
\hline EEM & Prof. Paulo de Assis Ribeiro \\
\hline EM & Vera Lúcia Pereira Leite \\
\hline EM & Professor Roberto Lyra \\
\hline$E M$ & José Maria de Brito \\
\hline EM & Eulália Cardoso de Figueiredo \\
\hline EM & N. Sra. de Nazareth \\
\hline & CAIC Paulo Dacorso Filho \\
\hline
\end{tabular}

Fonte: Secretaria Municipal de Educação De Seropédica, 2013.

Torna-se importante, ainda, destacar os nomes das escolas, pois as denominações refletem muito da história da localidade por meio das homenagens aos personagens e sua relação com o processo de estruturação dos bairros. Algumas escolas receberam o nome do bairro onde se localizam. Muitas homenageiam personagens associadas à história regional - tanto de Itaguaí, como é o caso do ex-prefeito da cidade, José de Abreu, que nomeia uma escola no Bairro de Campo Lindo, quanto de Seropédica, em que o funcionário do Instituto Brasileiro de Desenvolvimento Florestal ${ }^{7}$ (IBDF), Luiz Leite de Brito, foi o homenageado.

Outras escolas receberam o nome de professores que trabalharam pela educação do bairro em que atuaram; alguns tributos são a cidadãos locais, ao trabalhador que construiu a antiga Rodovia Rio-São Paulo, assim como a um líder religioso. Este é o caso da E. M. Pastor Gerson Ferreira Costa, localizada no Bairro Esperança, inaugurada em agosto de 1980, durante a gestão do prefeito Abelardo Goulart, de Itaguaí. O patrono da escola, licenciado em Teologia e Filosofia, foi importante liderança religiosa e esteve presente ativamente ocupando vários cargos religiosos na região.

Luiz Leite de Brito foi um morador da região de Fonte Limpa, onde se localiza a escola de mesmo nome, e que cedeu a casa onde funciona a escola.

\footnotetext{
${ }^{6}$ Cabe registrar que apesar de muita pesquisa, algumas escolas não tiveram a data de criação e a origem de seus nomes encontradas.

7 O IBDF (Instituto Brasileiro de Desenvolvimento Florestal), um órgão vinculado ao Ministério da Agricultura, foi criado em 1967 e extinto em 1989. Hoje suas antigas finalidades são atribuições do IBAMA (Instituto Brasileiro do Meio Ambiente e dos Recursos Naturais Renováveis).
} 
Já a E. E. M Quintino Bocaiúva homenageia o jornalista e político brasileiro, nascido no município de Itaguaí, que alcançou projeção nacional desde os primórdios republicanos, no final do século XIX.

A última escola criada poucos anos antes da emancipação de Seropédica foi o Centro de Atendimento Integral à Criança (CAIC) ${ }^{8}$ Paulo Dacorso Filho, projeto educativo original idealizado no Governo Collor.

Em 1991, buscando um local que servisse de apoio aos estudantes dos cursos de licenciatura, a Universidade Federal Rural do Rio de Janeiro (UFRRJ) manifestou interesse em implantar um Centro Integrado de Atenção à Criança e ao Adolescente -CIAC, no interior de seu campus. Tal intenção fora expressa em Ofício do Reitor ${ }^{9}$. Assim, a gestão universitária entrou em contato com o governo federal, por intermédio do MEC, a fim de efetivar o projeto. O CIAC seria concretizado por meio de convênio entre a UFRRJ e o Ministério da Educação e dos Desportos, através da Secretaria de Projetos Educacionais Especiais, órgão vinculado à Presidência da República, conforme a Ata do Conselho Universitário (Consu) de $1993^{10}$.

Como previa o Projeto Minha Gente, a criação do CIAC de Seropédica respondia aos objetivos de buscar uma maior integração e atuação na comunidade local, o que vinha efetivamente ao encontro dos interesses expostos pela Universidade: criar um ambiente ideal para as licenciaturas, pois, à época, tais cursos mostravam-se carentes de espaços que favorecessem as suas atividades curriculares. Além de garantir uma nova instituição escolar em uma região carente do estado do Rio de Janeiro, mantendo um vínculo entre a universidade e a população,

(...) o CAIC constitui-se numa oportunidade fundamental para que a UFRRJ integre suas atividades acadêmicas desde a pré-escola até a pósgraduação, na busca da excelência e, sobretudo, da atuação na melhoria das condições de vida das comunidades abrangidas pela sua influência. (OFÍ́CIO no 253/1993)

O Projeto Minha Gente previa que os CIAC deveriam ser administrados pelas três instâncias administrativas. A gestão tripartite da escola, ao longo de sua trajetória, sempre foi uma tarefa difícil de ser encaminhada, assim como o convênio inicial estabelecido entre a universidade e os governos municipal de Itaguaí (Seropédica ainda era um distrito) e o do estado do Rio de Janeiro. O principal obstáculo apresentado pelos dois governantes incidia sobre a participação da universidade na gestão da escola (FONSECA, 2010, p. 33).

Poucas, então, são as escolas que não homenageiam personagens associados à memória local, como é o caso da escola E. E. M. Olavo Bilac, uma menção ao poeta brasileiro e defensor da república, e da E. M. Paulo Freire, professor renomado que empresta seu nome a uma instituição escolar nascida da luta popular de assentados na região. Nesse sentido, as instituições

\footnotetext{
${ }^{8}$ Centros Integrados de Atenção à Criança e ao Adolescente (CIAC), mais tarde chamados Centros de Atenção Integral à Criança e ao Adolescente (CAIC).

${ }^{9}$ Ofício 174/GR/UFRRJ de 24 de maio de 1991 da Reitoria, dirigido ao Secretário Nacional de Educação Superior.

${ }^{10}$ Deliberação no 4 de 16 de fevereiro de 1999, do Consu/UFRRJ.
} 
escolares contribuem para recuperar a memória local, desvelando importantes referências históricas da cidade. Assim, o que se observa é que os nomes das unidades escolares referem-se a pessoas que se destacaram, sobretudo, pelo trabalho.

\section{A constituição do sistema de ensino público seropedicense}

Atualmente, a maior responsabilidade política e administrativa tem recaído sobre a esfera municipal. A política de municipalização, em uma perspectiva descentralizadora, atende aos preceitos estabelecidos pelo Banco Mundial ${ }^{11}$, transferindo para os municípios brasileiros as principais tarefas atinentes à educação. Para compreender esse processo, buscamos apoio em Bertha do Valle (2008, p. 58):

A expressão municipalização do ensino deve ser entendida como a progressiva passagem para a responsabilidade municipal de encargos e serviços de educação, particularmente na área do ensino fundamental, passagem essa a ser levada a termo pelas legislações estadual e federal.

A carta constitucional vigente confirma a importância dos municípios ao determinar que a responsabilidade sobre 0 ensino fundamental cabe obrigatoriamente a eles, que ainda assumem a tarefa de assegurar a Educação Infantil. $\mathrm{O}$ artigo 18 da Constituição Federal afirma que a "organização políticoadministrativa da República Federativa do Brasil compreende a União, os Estados, o Distrito Federal e os Municípios, todos autônomos". Portanto, atualmente, os municípios são entes da federação, assim como os estados, assumindo na educação um papel preponderante, pois enfeixam a tarefa de gerir os primeiros anos de escolaridade da educação brasileira. Entretanto, do ponto de vista dos recursos financeiros, o município torna-se a esfera mais fragilizada da estrutura política, como é possível inferir no texto a seguir:

(...) sendo as políticas e a legislação federais, a sua aplicação nos municípios não partiu de consulta ou iniciativa dos professores, dos profissionais da educação, nem da comunidade escolar ou da população. Tal procedimento talvez explique a demora no seu atendimento e o desinteresse e desinformação dos professores e funcionários de apoio, sobre a composição dos conselhos de acompanhamento e gestão, sobre o plano municipal de educação ou acerca do regime de colaboração entre as três esferas - federal, estadual e municipal.

E na medida em que não há participação, as políticas continuam sendo determinadas de cima para baixo. (FARIA, 2012, p.247)

Como as políticas financeiras para a educação são determinadas por legislações federais, a comunidade municipal fica muito distanciada das

\footnotetext{
${ }^{11}$ O Banco Mundial é o organismo internacional que concede empréstimos para os países subdesenvolvidos, com a inclusão de investimentos no setor educacional, e que, sobretudo, a partir dos anos de 1970 vem estendendo suas ações no sentido de influenciar as políticas públicas nesse campo.
} 
disposições legais e sua participação acaba sendo bastante minimizada, as iniciativas populares são incipientes ou então ineficazes, e confirmam a fragilidade dos municípios nas questões financeiras.

A educação de Seropédica começou a se constituir efetivamente como uma rede de ensino a partir de 1997, no momento em que a região assumiu sua condição de município emancipado, autônomo, com seus poderes instituídos. Os representantes dos poderes executivo e legislativo haviam sido eleitos no ano anterior, mobilizando a população para iniciar a nova situação administrativa. Nessa época, a população do município atingia um quantitativo de 54.937, segundo os dados fornecidos pelo Instituto Brasileiro de Geografia e Estatística (IBGE).

Com a primeira gestão de governo, a educação começou a ser organizada na cidade a partir da formação de um sistema. Por sistema tomamos como referência a definição de Libâneo et alii (2003, p. 227), que define o termo como:

(...) um conjunto de elementos, de unidades relacionadas, que são coordenadas entre si e constituem um todo. Essa característica presume a existência de tensões e de conflitos entre os elementos integrantes. Por constituírem uma reunião intencional de aspectos materiais e não materiais, esses elementos não perdem sua especificidade, sua individualidade, apesar de integrarem um todo. Da mesma forma, embora se estruturem em um conjunto de organizações de ensino, as escolas não perdem sua especificidade de estabelecimentos que possuem determinadas características singulares e se inserem em determinadas regiões. Por sua vez, o conjunto de normas e leis que regulam a organização e o funcionamento de uma rede de escolas não perde sua identidade de normas e leis.

Assim, o que se depreende é a caracterização de sistema como um conjunto harmônico e coerente entre suas partes integrantes. Nesse caso, as escolas vêm constituir o sistema municipal de ensino público, sem que as unidades escolares percam as particularidades que as distinguem, que as singularizam, atuando de forma planejada e sistemática. Deste modo, os sistemas municipais de ensino compreendem todas as escolas mantidas pelo Poder público local, seus órgãos de educação, como Conselhos Municipais, Secretarias Municipais e as instituições privadas de educação infantil, que estão sob a responsabilidade da Secretaria Municipal de Educação. Vasconcelos (2003, p. 111) em seus estudos a respeito, afirma que esses se compõem de:

(...) escolas, prédios, equipamentos, bibliotecas, laboratórios, alunos, professores, funcionários, equipes administrativas e pedagógicas, currículos, conteúdos, metodologia, avaliação das instituições de educação, tanto públicas quanto privadas, de uma mesma rede de ensino.

Alguns autores analisam que o Brasil ainda não possui um sistema de ensino, apesar de toda a legislação vigente referir-se ao termo. Para o pleno funcionamento, os sistemas de ensino precisam manter em articulação entre si, o que ainda não ocorre. Portanto, os sistemas federal, estaduais e municipais, independentes entre si, atendem isoladamente aos preceitos legais. Saviani 
utiliza a expressão sistema educacional, pois a compreende como a mais abrangente, refletindo que:

a) do ponto de vista da entidade administrativa, o sistema educacional pode ser classificado em: federal, estadual, municipal, particular etc.;

b) do ponto de vista do padrão, em: oficial, oficializado ou livre;

c) do ponto de vista do grau de ensino, em: primário, médio, superior;

d) do ponto de vista da natureza do ensino, em: comum ou especial;

e) do ponto de vista do tipo de preparação, em: geral, semiespecializado ou especializado;

f) do ponto de vista dos ramos de ensino, em: comercial, industrial, agrícola etc. (SAVIANI, 1999, p. 121)

Tal imprecisão do termo e, muitas vezes, o uso incorreto da expressão explica-se em função de sua não efetiva vigência. Mais uma vez, Saviani, a respeito, afirma que:

(...) a atitude que tem prevalecido entre os educadores em geral e especialmente entre os legisladores tem sido a de evitar a questão relativa ao esclarecimento preciso do conceito de sistema, considerandoo como algo constantemente referido mas cujo sentido permanece sempre implícito, supostamente compreendido mas jamais assumido explicitamente. (SAVIANI, 1999, p. 121/122)

A investigação assinala que a Constituição Federal de 1988 permitiu aos municípios a instituição de seus sistemas de ensino com autonomia, inclusive para a formulação de políticas públicas para a educação infantil e para o ensino fundamental, conforme pesquisa de Souza e Faria (2003, p. 65/66). Em decorrência do disposto pela legislação federal, estes assumiram compromissos maiores que:

[...] em face da atribuição de uma maior autonomia aos Municípios, estes se viram diante de desafios concernentes: i) à sua participação no regime de colaboração, de forma solidária, junto aos Estados e à União; ii) à previsão da Educação Municipal, enquanto capítulo específico, na formulação de suas Leis orgânicas (Los); iii) à elaboração dos Planos Municipais de Educação (PMEs); e, ainda, iv) à constituição de seus Conselhos de Educação e dos Conselhos de Acompanhamento de Controle Social (CACS).

Entretanto, para Saviani, a Carta Magna utiliza o termo sistema no lugar de redes de ensino por este se aplicar exclusivamente às esferas estaduais e federal, pois são essas as instâncias administrativas que possuiriam a prerrogativa garantida de legislar sobre o tema da educação.

Ao que tudo indica, o artigo 211 da Constituição Federal de 1988 estaria tratando da organização das redes escolares que, no caso dos municípios, apenas por analogia são chamadas aí de sistemas de ensino. Com efeito, sabe-se que é muito comum a utilização do conceito de sistema de ensino como sinônimo de rede de escolas. Daí falar-se em sistema estadual, sistema municipal, sistema particular etc., isto é, 
respectivamente, rede de escolas organizadas e mantidas pelos estados, pelos municípios ou pela iniciativa particular. (SAVIANI, 1999, p. 123)

Por outro lado, a Lei de Diretrizes e Bases da Educação Nacional (LDBEN), promulgada em 1996, prevê a possibilidade de municípios legislarem no tocante ao quesito educação. Portanto, a Lei 9394/96 utilizou-se do termo sistema atribuindo aos municípios o direito de baixar normas complementares para seu sistema de ensino. Ao mesmo tempo, a LDBEN permite também que os municípios possam se integrar aos sistemas estaduais, caso considerem a melhor opção, conforme se pode inferir pela leitura do inciso III e do parágrafo único, do artigo abaixo:

Art. 11. Os Municípios incumbir-se-ão de:

I - organizar, manter e desenvolver os órgãos e instituições oficiais dos seus sistemas de ensino, integrando-os às políticas e planos educacionais da União e dos Estados;

II - exercer ação redistributiva em relação às suas escolas;

III - baixar normas complementares para o seu sistema de ensino;

IV - autorizar, credenciar e supervisionar os estabelecimentos do seu sistema de ensino;

$\mathrm{V}$ - oferecer a educação infantil em creches e pré-escolas, e, com prioridade, o ensino fundamental, permitida a atuação em outros níveis de ensino somente quando estiverem atendidas plenamente as necessidades de sua área de competência e com recursos acima dos percentuais mínimos vinculados pela Constituição Federal à manutenção e desenvolvimento do ensino.

VI - assumir o transporte escolar dos alunos da rede municipal.

Parágrafo único. Os Municípios poderão optar, ainda, por se integrar ao sistema estadual de ensino ou compor com ele um sistema único de educação básica. (Lei 9394/96)

\section{Para finalizar, algumas considerações}

O sistema de ensino de Seropédica instituiu-se a partir das legislações municipais. O texto da Lei Orgânica de Seropédica trata sobre Educação em capítulo próprio, inserido no Título V, intitulado "Da Ordem Econômica e Social". O termo sistema de ensino aparece no texto legal tanto quanto a expressão rede de ensino, assinalando a imprecisão a que se refere Saviani (1999), conforme explicitado anteriormente. A Lei Orgânica de Seropédica faz menção a sistema de ensino no artigo 140, enquanto no artigo anterior utiliza-se da expressão rede de ensino, que aparece em alguns de seus incisos, como se pode observar nos trechos destacados abaixo:

Art. 139 - O dever do Município com a educação será efetivado mediante garantia de:

(...)

$\S 30$ - Recensear periodicamente as crianças em idade escolar, com a finalidade de orientar a política de expansão da rede pública municipal de educação e investimentos.

(...)

$\S 5^{\circ}$ - Instituir nas escolas da rede municipal, ação cultural integrada à política educacional do Município, pelos seus órgãos específicos, ficando 
a orientação dessa política cultural educacional a cargo da Secretaria Municipal de Educação.

(...)

Art. 140 - O sistema de ensino municipal assegurará aos alunos necessitados condições de eficiência escolar. (Lei Orgânica de Seropédica, 1997)

Assim, o município de Seropédica optou por criar o seu próprio sistema educacional, pois se refere a uma rede própria e não à incorporação ao sistema estadual de educação. A cidade atendeu ao previsto pelo Parecer 30 da Câmara da Educação Básica, do Conselho Nacional de Educação, que definiu o termo sistema de ensino, definitivamente, como:

"(...) o conjunto de campos de competências e atribuições voltadas para o desenvolvimento da educação escolar que se materializam em instituições, órgãos executivos e normativos, recursos e meios articulados pelo Poder Público competente, abertos ao regime de colaboração e respeitadas a normas gerais vigentes. Os municípios, pela Constituição de 1988, são sistemas de ensino." (BRASIL. MEC. CNE. CEB, 2000, p. 13/14.)

Portanto, apesar de autores, entre educadores e juristas, discutirem a imprecisão do termo, do ponto de vista legal, a educação brasileira organiza-se em sistemas de ensino nos diferentes âmbitos administrativos: municipal, estadual e federal.

Além da Lei Orgânica, a cidade possui duas outras legislações que normatizam sobre o tema da educação. O Regimento Escolar e o Plano de Carreiras e Remuneração dos Profissionais da Educação do Município, aprovado pela Câmara Municipal de Vereadores. A Secretaria Municipal de Educação é o órgão responsável por coordenar e planejar as ações do sistema municipal de educação - foi criada tão logo a administração municipal instalou-se; funcionava nos primeiros anos em uma grande sala do prédio da sede do executivo. Lá se instalaram, além da Secretária e de sua subsecretária, mais quatro funcionários, quais sejam: uma Diretora de Educação, com a responsabilidade de coordenar as questões pedagógicas, e uma Diretora Administrativa, além de dois auxiliares administrativos.

Partindo do que foi analisado neste trabalho, a despeito de as instituições escolares terem surgido da necessidade criada pela presença da instituição de ensino superior, a relação entre as escolas públicas municipais e a universidade encontra-se, ainda, quase inexistente. Sinaliza, assim, que a universidade se mantém distanciada de sua cidade, apartada de seu cotidiano, do dia a dia da população, e contribuindo ainda muito pouco para o seu desenvolvimento e educação de sua gente. A relação entre Seropédica e a UFRRJ é ainda muito tímida, restrita em suas possibilidades, pouco incrementada. Mas esse processo é dinâmico, acha-se em constante movimento, e não se pode afirmar, portanto, que tal cenário não se modifique. A expectativa é de que se estabeleça uma maior interação no sentido de que cidade e universidade se favoreçam desse contato mútuo.

\section{Referências bibliográficas}

Caderno eletrônico de Ciências Sociais, Vitória, v. 3, n. 2, p. 67-80. 
BLOCH, Marc. Introdução à História. 2aed. Publicações Europa-América, 1974.

FARIA. Roberto. Educação Municipal, a intervenção das políticas federais: reflexos na região serrana do estado do Rio de Janeiro. Rio de Janeiro: Quartett: CESGRANRIO, 2012.

FEBVRE, Lucien. Combates pela História. Vol. I. Lisboa: Ed. Presença, 1977.

FONSECA, Marília Massard da. Resgate da História de Implantação do Centro de Atenção Integral à Criança "Paulo Dacorso Filho" na UFRRJ e a perspectiva de sua transformação em um centro de ensino e pesquisa aplicado à educação agro ecológica. Dissertação de Mestrado, PPGEA/UFRRJ, Seropédica, 2010.

FREITAS, Pâmela Travassos de. Os arquivos escolares e seu papel na história da educação. Disponível em: www.utp.br/lep/N3/artigos/os_arquivos.pdf. Acesso em: 02 de dezembro de 2012.

LIBÂNEO, José Carlos, OLIVEIRA, João Ferreira, TOSCHI, Mirza Seabra. Educação Escolar: políticas, estrutura e organização. São Paulo: Cortez, 2003.

SAVIANI, Dermeval. Sistemas de ensino e planos de educação: o âmbito dos municípios. Educação \& Sociedade, ano XX, no 69, p. 119-136, dez/99.

SOUZA, Donaldo Bello, FARIA, Lia Ciomar M. O Processo de construção da Educação Municipal pós-LDB 9394/96: políticas de financiamento e gestão. In: SOUZA, Donaldo Bello e FARIA, Lia Ciomar Macedo de (Orgs.). Desafios da Educação Municipal. Rio de Janeiro: DP\&A, 2003, p. 47- 84.

VASCONCELOS, Maria Celi Chaves. Conselhos Municipais de Educação: criação e implantação em face das novas atribuições dos sistemas municipais de ensino. In: SOUZA, Donaldo Bello e FARIA, Lia Ciomar Macedo de (Orgs.). Desafios da Educação Municipal. Rio de Janeiro: DP\&A, 2003, p. 107-122.

VALLE, Bertha de B. R. Controle social da educação: aspectos históricos e legais. In: SOUZA, Donaldo Bello (Org.). Conselhos municipais e controle social da educação: descentralização, participação e cidadania. São Paulo: Xamã, 2008, p. 53-74.

\section{Fontes primárias}

BRASIL. Congresso Nacional. Lei no 9394, de 20 de dezembro de 1996. Estabelece as Diretrizes e Bases da Educação Nacional. Diário Oficial [da] República Federativa do Brasil. Poder Executivo. Brasília, DF, n0248, Seção 1, p. 27833, 23 dez. 1996.

Parecer no 30, de 5/10/2000, do Conselho Nacional de Educação. Parecer orientador a respeito do entendimento sobre o município enquanto sistema.

SEROPÉDICA. Lei Municipal no 316 de 2005. Dispõe sobre o Plano de Carreiras e Remuneração dos Profissionais da Educação do Município de Seropédica. 2005.

Lei Orgânica. Câmara Municipal de Seropédica. Aprovada em 30 de junho de 1997. 
- Secretaria Municipal de Educação. Livros de Ponto de Funcionários e Professores. Escola Municipal Pastor Gerson Ferreira Costa.

- Secretaria Municipal de Educação. Projeto Político Pedagógico. Escola Municipal Pastor Gerson Ferreira Costa. Seropédica. 2012.

Secretaria Municipal de Educação. Departamento de Projetos. Relação das Unidades: Escolas Municipais 2011 - 2012.

UFRRJ. ATA DO CONSU. 16 DE FEVEREIRO DE 1993. Aprovação do convênio entre a Universidade Federal Rural do Rio de Janeiro e o Ministério da Educação e do Desporto, através da Secretaria de Projetos Educacionais Especiais.

UFRRJ. OFÍCIO No. 253/ GR / UFRRJ/ 28 de julho de 1993. Da Reitoria dirigido ao Secretário de Projetos Especiais. 1993. 